\title{
Questioning the technological fix to climate change: Lay sense-making of geoengineering in Sweden
}

\author{
Victoria Wibeck, Anders Hansson and Jonas Anshelm
}

\section{Linköping University Post Print}

\section{Tweet}

N.B.: When citing this work, cite the original article.

Original Publication:

Victoria Wibeck, Anders Hansson and Jonas Anshelm, Questioning the technological fix to climate change: Lay sense-making of geoengineering in Sweden, 2015, Energy Research \& Social Science, (7), May, 23-30. http://dx.doi.org/10.1016/j.erss.2015.03.001

Copyright: 2015 Elsevier Ltd.

http://www.sciencedirect.com/

Postprint available at: Linköping University Electronic Press http://urn.kb.se/resolve?urn=urn:nbn:se:liu:diva-119732 


\title{
Questioning the technological fix to climate change - Lay sense-making of geoengineering in Sweden
}

\author{
Abstract \\ This paper explores how Swedish laypeople make sense of emerging ideas of the large-scale \\ deliberate technical manipulation of the global climate, known as geoengineering (GE). The paper is \\ based on semi-structured focus group interviews with open-ended questions, allowing participants to \\ express their spontaneous thoughts about GE. Although the focus group participants expressed great \\ concern about climate change, GE was largely met with a sceptical, negative response. Participants \\ perceived GE to: have negative environmental side-effects, address the symptoms rather than causes \\ of climate change, create moral hazard and give rise to various governance challenges. Participants \\ did not just reject the idea of GE outright; rather, social representations started to form in the focus \\ groups through testing and negotiating arguments both pro and contra GE research and deployment.
}

\section{Keywords}

Geoengineering, climate change, focus groups, social representations, public engagement 


\section{Introduction}

Geoengineering (GE) refers to large-scale intentional technical manipulations of the Earth's climate system either by reflecting sunlight or removing carbon dioxide from the air. Examples of proposed technologies include stratospheric sulphur particle injection, marine cloud brightening, space mirrors, ocean iron fertilization, biochar and the direct engineered capture of carbon dioxide from the air (Royal Society, 2009).

Until 2006, GE was more or less considered unthinkable both in the climate change policy arena and in science. ${ }^{1}$ In 2006 the Nobel laureate Paul Crutzen initiated a special issue of Climatic Change calling for active research into GE. He claimed that 'the very best would be if emissions of the greenhouse gases could be reduced so much that the stratospheric sulfur release experiment would not need to take place. Currently, this looks like a pious wish' (Crutzen, 2006: 217). This is still a widespread perspective in both public and scientific debates, but it is generally acknowledged that the likely far-reaching environmental consequences of GE are poorly understood, raising ethical and governance concerns as well as questions about these options' technical feasibility (e.g. Hamilton, 2013; Anshelm and Hansson, 2014).

The Intergovernmental Panel on Climate Change (IPCC) first included GE in its assessment reports in 2013. The inclusion of GE, deemed 'largely speculative and unproven' only a few years ago (IPCC, 2007: 15), can be interpreted as signifying the normalization of these options. This opens up the possibility that GE may constitute an additional and potentially complementary category of options to address global warming, besides mitigation and adaptation strategies. However, the public's awareness of this potentially radical shift in climate change politics is very low (e.g. Mercer et al., 2011; Merk et al., 2014; Wright et al., 2014), motivating emerging social science research into public deliberation, public perceptions and engagement with GE. So far, this research has had a strong UKUS focus (cf. Merk et al., 2014), prompting calls to explore GE assumptions and discourses in wider cultural contexts (Porter and Hulme, 2013).

\footnotetext{
${ }^{1}$ However, this does not mean that GE ideas have not surfaced earlier. For instance, Fleming (2010) argues that weather modification has been discussed for more than a century.
} 
In response to the calls to broaden the geographical and cultural scope of social science GE research, this paper aims to explore lay sense-making of GE in Sweden. More specifically, and unlike other social science studies of public responses to GE, this paper starts from a social representations approach, which provides tools for analysing communicative processes involved in the formation of lay understandings (Moscovici, 1984). Sweden exemplifies a country with limited scientific, policy and public debate on GE, making it an appropriate setting for exploring early public reactions to the idea of engineering the climate. At this early stage of research into Swedish lay understandings, we did not evaluate specific GE technologies or their various potentials and characteristics, but instead wanted study participants to explore the overarching idea of intentional grand-scale technical manipulation of the global climate. This is also how GE has so far usually been described in the international public media (Anshelm and Hansson, 2014).

\section{Public understanding of geoengineering: An emerging research field}

Previous research into the public understanding of GE can be broadly divided into two categories. The first is primarily quantitative and maps public opinions or perceptions. A few surveys have estimated lay knowledge or perceptions of GE (NERC, 2010; Kahan et al., 2012; Pidgeon et al., 2012; Merk et al., 2014; Wright et al., 2014; see also Poumadere et al., 2011), finding that only a few per cent of respondents had heard of GE and that even fewer knew about its basic principles. A survey of public perceptions of GE in the US, the UK and Canada found that only $8 \%$ of respondents were somewhat familiar with GE (Mercer et al., 2011). This study concluded that public opinion is in its formative stage and is sensitive to changes in framing and to future information on risks and benefits. In a major two-nation study of the USA and the UK, Kahan et al. (2012) investigated how individuals relied on cultural meanings in forming risk perceptions. When exposed to GE information, respondents became somewhat more concerned about climate change risks.

The second category of studies applies qualitative approaches and primarily a public engagement perspective. Pidgeon et al. (2012) have performed both a qualitative interview study and a survey on 
GE in the UK. In the interview study, researchers spent five minutes interviewing each informant about GE. Their interviews and questions were similar in structure to those used here, though we spent considerably longer discussing GE and closely related issues. In another study, Pidgeon et al. (2013) applied a deliberative method to embed public dialogue in the innovation process. For two days their informants discussed GE, specifically, solar radiation management (SRM), in three workshops. The participants' main concerns were safety and unintended impacts, methodology and justification, knowledge limitations, governance and communication, overlapping the concerns identified in the present study.

Macnaghten and Szerszynski (2013), taking a critical stance to the role of social science in public engagement, applied a deliberative focus group method in the UK, using an approach similar to Pidgeon et al's (2012) by gradually introducing GE (SRM), not only to reproduce dominant framings but also to understand informant responses and what shaped them. Most importantly - and touching on the critical dimension - the researchers tried to interpret the governance implications of responses. Unlike previous studies, Macnaghten and Szerszynski's (2013: 472) participants were claimed 'to arrive at more consistently sceptical positions about the prospect of geoengineering'. Also, participants who initially conditionally accepted SRM became more sceptical when, what the authors call possibly more realistic, framings were introduced during the interviews. This change was tentatively explained by the observation that the participants then deemed deployment as unfeasible. One conclusion they draw is that the more the participants know about SRM the more sceptical they become.

There is ongoing discussion whether study participants need to be well informed about the technologies in focus. Daamen et al. (2006) have questioned whether quick responses based on limited knowledge of technologies would provide valuable insight into public understandings. Their experimental study found that lay opinions, in this case regarding carbon capture and storage, could easily be changed by letting respondents perform irrelevant and annoying tasks for a few minutes. By contrast, Carr et al. (2013) and Pidgeon et al. (2013) claim that it is not a prerequisite that participants 
have extensive knowledge of the technology in question, as even lay knowledge and limited input of basic knowledge from an expert can lead to well-reasoned argumentations and positions. Pidgeon et al. (2012) maintain that laypeople tend to draw on a range of cultural narratives and personal experiences that can be related to the scientific topic being discussed in order to construct an understanding. In the present study, we pay particular attention to that phenomenon.

Aware of Daamen et al.'s (2006) results, we paid special attention to group dynamics, for example, how respondents reacted to new information and other respondents' counterclaims. Also, the present study takes low awareness of GE as a starting point in studying emerging social representations among laypeople concerning something they have likely never heard of. We argue that exploring social representations of GE can help reveal lay assumptions and concerns about GE. The limited moderator intervention in our focus groups also enables analysis of how meaning is formed among the study's participants.

The novel contributions of this paper lie primarily in broadening the geographical and cultural scope of social science GE research beyond the current UK-US focus. In this respect, Sweden provides an interesting case of public GE ignorance. Also, the paper employs a more open-ended approach to focus group interviews, compared to most previous studies of public understandings of GE. This allows exploration of focus group participants' spontaneous sense-makings as well as of their responses to specific framings (in particular the climate emergency argument) introduced by the focus group moderators in the later parts of the interviews (see below). The paper is also novel in using a social representations approach, which to our knowledge has not been done previously in studies related to climate engineering. 


\section{Methods and materials}

This paper is inspired by a dialogical interpretation of social representations theory (e.g. Moscovici, 1984; Marková et al., 2007). This theory concerns lay sense-making through the formation of shared representations of the surrounding world (Moscovici, 1984) - in other words, 'how people make sense of unfamiliar information' (Smith and Joffe, 2012: 2). A social representation can be defined as 'a system of values, ideas and practices' regarding a given social object (Moscovici, 1973: xiii) or as 'mundane understandings which are commonsensical in character' (Olausson, 2011: 283). When interpreted dialogically, i.e. focusing on how representations are formed and negotiated in social interaction between individuals (Wibeck, 2014), social representations theory is especially helpful in analysing how abstract science-based knowledge becomes commonsense knowledge with time. Two communicative processes are particularly important in the formation of social representations: 'anchoring' and 'objectification' (Moscovici 1984). Anchoring concerns how new phenomena are compared to and classified into well-known categories (Höijer, 2010), while objectification concerns making abstract concepts more concrete, e.g. through the use of metaphors or prototypical examples (Wibeck, 2014).

The social representations approach has informed our choice of focus group methodology, as focus groups are recommended when the object of study is new to the participants and when social representations of it have still not become conventionalized (Marková et al., 2007). We hypothesized that GE would be largely unknown to the study's participants, as there had been virtually no media coverage of this topic in Sweden at the time of the interviews. Under such circumstances, focus groups may provide a setting in which interacting participants try out understandings and arguments, providing opportunities to observe the joint formation and negotiation of social representations (Marková et al., 2007). In other words, focus groups provide a means of gaining insight into mutual meaning-making in action (Wilkinson, 1998). 
In this paper we are particularly concerned with the content of early social representations of emerging, contested GE technologies, while a forthcoming paper will explore processes of forming such representations through anchoring the new in well-known categories or through objectifying abstract science-based knowledge (cf. e.g. Höijer, 2010; Smith and Joffe, 2012; Wibeck, 2014).

The analyses presented here are based on eight focus group interviews with 45 Swedish laypeople, conducted between May and September 2013. A focus group discussion is a facilitated discussion within a relatively small group of participants (here, five to seven per group) on a predetermined topic (e.g. Morgan, 1997). Although the type of focus group study used for this paper includes a limited number of participants, the method is claimed to be beneficial for in-depth analyses of sense-making on new and complex phenomena (Marková et al, 2007). Focus groups are intended to take advantage of the interaction between participants to explore, in depth, their recurrent and differing arguments, standpoints and opinions (Kitzinger, 1994; Morgan, 1997; Wibeck et al., 2007).

To facilitate interaction between the participants, the focus groups were internally homogeneous in terms of participant age and educational background (cf. Jarrett, 1993). The groups shared similarities in that they were from the same geographical region, most of them living in cities. Variation between groups was sought in order to achieve as broad a 'map of opinions' as possible and to gain a wide range of perspectives on GE (see Table 1). The participants were 16-88 years old and had varied educational and occupational backgrounds. All groups included both women and men, although more women than men participated in the study.

\section{[PLEASE INSERT TABLE 1 ABOUT HERE]}

A research assistant recruited the participants using topic-blind recruitment (cf. Macnaghten and Szerszynski, 2013), meaning that GE was not mentioned in the invitation. We did not want the participants to prepare for the discussions by seeking information, but wanted to investigate whether they were familiar with GE and to explore their spontaneous reactions and associations. We therefore chose to invite the participants to group interviews on global environmental problems and how these 
could be handled. We acknowledge that revealing the focus on global environmental problems might have affected the group composition, in that people interested in environmental issues might have been more inclined to participate. This could be a potential bias in the data. However, in analysing the data, we found that the participants varied greatly in whether or not they claimed to be interested in environmental issues. Several informants even explicitly declared no particular interest in environmental issues.

Each focus group met once and each discussion lasted 40-90 minutes. Two of this paper's authors moderated the groups. The focus group discussions were audio recorded and transcribed verbatim. The discussions were conducted in Swedish, but for the purposes of this paper all quotations have been translated into English and adapted to written language conventions. The names of participants have been replaced with pseudonyms to ensure confidentiality.

Our approach to focus group interviewing entailed little moderator involvement. We constructed a semi-structured topic guide with open-ended questions that we posed if participants did not spontaneously raise the related issues. The topic guide started from a broad discussion of global environmental issues and moved, via climate change, to GE technologies. We also allowed participants to raise additional questions not in our topic guide but that concerned the broader topic of the focus group.

The approach taken in this study is open-ended in that it explores laypeople's spontaneous reactions to GE. Nonetheless, focus group discussions of a controversial topic such as GE, largely unknown to participants before the focus group session, can hardly be facilitated without the moderator at least somewhat framing GE to the participants. Our strategy was to start the discussions with open-ended questions, subsequently to provide information on and examples of GE technologies and to explore participant reactions to some of the dominant framings of GE in the literature. Three particular types of moderator interventions might have influenced the focus group discussions: 1) the specific GE technologies selected to exemplify the solar radiation management and carbon dioxide removal approaches; the GE technologies mentioned by the moderators - though not in detail - included space mirrors, stratospheric sulphur injection, marine cloud brightening, rooftop painting, crop brightening, 
direct air capture and ocean iron fertilization; 2) the introduction of the climate emergency frame, which positions GE as a response to climate emergencies (a 'plan B') and 3) the occasional mentioning of popular expressions explaining some of the technologies, such as 'artificial trees' or 'artificial clouds'. Both the climate emergency frame and framing GE as analogous to 'natural' phenomena such as trees or volcanic eruptions have been suggested to make laypeople more likely to support GE (Corner et al., 2013; Markusson et al., 2013). Since these ways of framing GE are common in international public debate on GE (Anshelm and Hansson, 2014), we found it relevant to explore how the focus group participants would react to them.

The data were analysed using thematic content analysis (Marková et al., 2007; Wibeck et al., 2007) in the following steps: 1) reading all transcripts in their entirety to divide them into segments, based on where topic shifts could be identified; 2) coding the content of the segments by assigning labels to them, i.e. nouns or nominal phrases summarizing the content of the segment; 3) identifying recurrent sub-topics in the coded list of segments and 4) identifying recurrent themes that capture several subtopics and that constitute a more abstract summary of the content of the focus group discussions.

\section{Results}

\section{Climate change and geoengineering}

The focus group discussions started with the moderator asking: 'What comes to mind when you hear the words "global environmental problems"?' The environmental issues mentioned by the participants included climate change, pollution and ozone depletion. Nevertheless, it was evident that all focus groups perceived climate change as the greatest environmental risk facing contemporary society. When further discussing their spontaneous associations with climate change, a recurrent pattern across the groups was that the participants highlighted dramatic climate change effects distant in time and space. When discussing climate change in general, the focus group participants expressed high confidence that science would be able to explain its causes and predict its future impacts. 
Overall, the participants perceived climate change as a serious threat to human societies and ecosystems, and expressed considerable pessimism about the future of the environment. To mitigate climate change, the participants emphasized the need for individual lifestyle change, societal transformation and limited growth. In addition, the need to develop low-carbon energy technologies was highlighted. However, the role and ability of politicians to respond to the challenges of climate change, for example, through international negotiations, was repeatedly questioned in the focus groups, and the participants claimed to have little trust in politicians in this respect.

After discussing environmental issues in general and climate change in particular, the participants were briefly introduced to the topic of GE. As expected, GE was largely unknown to the participants before participating in the focus groups. When asked whether they had heard of GE, only thirteen per cent of the participants answered in the affirmative. However, when describing to the other participants the GE technologies they were familiar with, they all either could not answer or described technologies that fall outside the range of GE technologies identified in the scientific literature (e.g. Royal Society, 2009; IPCC, 2013).

\section{Side-effects and the limits of science}

When briefly introduced to GE, a recurrent argument in the focus groups was that deploying GE technologies would result in unpredictable negative side-effects due to changes in ecosystems. In all groups but one (FG 7), the participants expressed concerns that deploying GE would alter ecosystem balance and thus further degrade global ecological conditions. For example, in one focus group (FG 8), one informant claimed that GE technologies would create 'pollution on the macro scale'. In comparing GE with pollutants such as DDT or waste dumped in the Baltic Sea, the participants in this group argued that GE was a short-sighted strategy. Similarly, participants in other groups stated that deploying GE technologies would not be sustainable in the long run.

A related and recurrent view of GE was that it was 'unnatural' or 'artificial', which the participants found problematic. In other words, GE was seen as a way of 'messing with nature' (cf. Corner et al., 2013). This might be related to the moderator's use of expressions found in public discourse, such as 
'artificial trees' or 'artificial clouds'. Contrary to what Corner et al. (2013) found, i.e. that using such 'natural' analogies to describe GE might make people more supportive, our focus group participants seem to have found the word 'artificial' problematic. An underlying assumption in the focus group discussions was that what was 'natural' was also good. This led some focus group participants to state that they saw all manipulation of nature as fundamentally wrong. Some also declared that humankind should realize its limits and refrain from 'playing God'.

In discussing the ethical, legal and social implications of GE, Corner and Pidgeon (2010: 32) argued that 'concerns about whether scientists and engineers have the capacity to safely mitigate the unintended technical and environmental consequences of geoengineering will play a central role in the debate'. Such concerns were key issues in our focus groups, in which the risk of unforeseen consequences and the threat to ecosystem balance often led the participants to raise epistemological objections to GE. As noted above, when discussing global environmental problems in general and climate change in particular, focus group participants expressed great trust that the scientific community would produce relevant and credible knowledge. As the discussion shifted to GE, however, the expressed level of trust in science diminished. The participants then instead expressed views regarding the limits to science's ability to foresee negative side-effects.

Across the focus groups, participants emphasized that the complexity of ecosystems made it impossible to produce satisfactory knowledge or forecast the exact ecological consequences of engineering the climate. No individual researchers were perceived to be able to judge the ecosystem effects. Moreover, in several groups, participants raised doubts as to whether it was in principle possible to obtain enough knowledge to justify deploying GE technologies. Along similar lines, some participants assumed that scientists could not possibly know the long-term effects of ocean iron fertilization or stratospheric aerosol injection, and that this ignorance constituted an enormous and insuperable problem of GE. Others noted that GE technologies were untested and maybe even impossible to test before deployment. This led some participants to conclude that GE was speculative and comparable to science fiction - a science-based fantasy hardly deserving consideration given the growing seriousness of global warming. 
It is noteworthy that GE was not always immediately rejected in the focus groups, but that

participants' opinions that GE entailed environmental risks and scientific uncertainty often came in response to arguments favouring GE. An example of such a meaning exchange comes from the focus group consisting of university students:

\section{Example 1:}

\begin{tabular}{|l|l|l|}
\hline 78 & Eric: & $\begin{array}{l}\text { It kind of feels safe that there is ... that they can calculate whether the } \\
\text { greenhouse effect has gone too far. That it has passed some tipping point. So } \\
\text { if it existed and if we theoretically could fix it if we only could produce the } \\
\text { technology and had the money to do this, it .. }\end{array}$ \\
\hline 79 & Sarah: & $\begin{array}{l}\text { I still think it's a bit disconcerting because you don't know the effects. Or, as } \\
\text { you said, what would happen [inaudible]? }\end{array}$ \\
\hline 80 & Eric: & Something else is guaranteed to go to blazes as well. \\
\hline 81 & Sarah: & Yes. \\
\hline 83 & Peter: & $\begin{array}{l}\text { This also means that you are trying to control nature. You are trying to } \\
\text { control the ecosystems in nature, and that will never work. We will never be } \\
\text { able to control the Earth or its ecosystems. I believe that nature is far too } \\
\text { complex for humans ever to understand. I don't think it will work. }\end{array}$ \\
\hline 84 & Sarah: & $\begin{array}{l}\text { Never say never. We might well be able to control it in the future, because } \\
\text { we can clone sheep and we can do so much that we never thought we could } \\
\text { do before. }\end{array}$ \\
\hline 85 & $\begin{array}{l}\text { I think that's just a perspective. We also want to control cancer, or to cure } \\
\text { diseases - we try to do this and that. Then we also want to save our Earth. } \\
\text { But sometimes perhaps it will strike back. }\end{array}$ \\
\hline 86 & Peter: & $\begin{array}{l}\text { I think that's possible ... } \\
\text { We can't even grow mushrooms, or I mean chanterelles, because it's too } \\
\text { complex. The simplest thing on earth and we can't grow chanterelles ... We } \\
\text { can clone sheep and we can do a lot, but we still can't grow chanterelles. }\end{array}$ \\
\hline
\end{tabular}

(FG 2)

Example 1 illustrates how social representations of GE were formed through negotiating standpoints between the focus group participants. It also illustrates how the participants responded to the climate emergency argument. In turn 78, Eric refers to this argument when stating that GE research would make one feel safer in the event of a climate catastrophe. This argument, however, is immediately contradicted by Sarah, who in turn 79 argues that GE is disconcerting, because its environmental impacts are unknown. When presented with this argument, Eric changes his standpoint, agreeing with Sarah that GE is likely to make other things go wrong (turn 80). In turn 82, Peter adds to this argument against GE by stating that ecosystems are too complex ever to be controlled or even understood by humans. This is contradicted by Patrick in turn 83 , who draws an analogy between 
controlling the climate and cloning sheep to make the point that scientists have previously achieved things that no one believed would be possible. Sarah then continues with another analogy between curing cancer and saving the earth (turn 84); unlike Patrick, she ends up concluding that at some point these human ambitions will cause the Earth to strike back. Patrick's response in turn 85 is somewhat ambiguous: either he is conforming with Sarah's view or he is pursuing his argument that it will eventually be possible to control global climate. Peter, however, interrupts Patrick to pursue the argument that humankind will never have the capacity to control complex ecosystems (turn 86). To back up his argument, he cites the example of difficulties growing chanterelles, which he claims has proven to be beyond human control.

Example 1 illustrates how the participants formed their representations in interaction with other participants, questioning each other's standpoints and building on each other's arguments. By bringing in analogies with other, better-known phenomena such as sheep cloning, curing cancer, or the failure to grow chanterelles, they anchored their views of GE, although they were unfamiliar with the topic before the focus group session and although they were not given abundant information by the moderator. This observation leads us to conclude that analyses of the content of social representations should not be decoupled from analyses of how these representations are formed. Example 1 illustrates a recurrent pattern in our focus groups, namely, that when arguments favouring GE research (e.g. the climate emergency argument) were introduced, by either the moderator or a participant, these arguments were explored but then largely discarded, for example, due to the risk of unknown ecological side-effects and limitations in predicting impacts.

\section{Treating the symptoms rather than causes of climate change}

Another recurrent theme in the focus groups was the participants' view of GE as a short-sighted approach. It was claimed that the fundamental problem with GE was that deploying GE technologies would address the symptoms rather than the causes and therefore not help solve the problem of climate change. Instead, the participants feared that GE would enable business as usual, and allow current high greenhouse gas (GHG) emissions to continue or even increase. Along similar lines, some 
participants interpreted GE research and deployment as a 'sign of surrender' or a 'panic action' (FG 5) of societies unwilling or unable to reduce GHG emissions. By contrast, in all focus groups, continued and increased emissions reduction was seen as key to tackling climate change.

Some participants claimed that GE research and deployment would lead to a false sense of security because transforming systems for energy production, transport, production and consumption might then not be seen as necessary in a climate-engineered world. Other participants feared that GE would lead to undesired 'upscaling' rather than 'downscaling' of consumption (FG 8), and one participant asked when humanity would realize that 'we can do with much less' (FG 8). Another quotation illustrating this line of reasoning comes from one group of middle-aged citizens:

\section{Example 2:}

This is starting at the wrong end. Sure, if there is an emergency it would be great if you could ... that there are ways to cool the Earth, but that doesn't take away the need to cut emissions. That is what creates the chimera that you can just keep going like before. (FG 5)

In this and similar sequences of the focus group discussions, the participants addressed the 'moral hazard' argument, which has been discussed at length in social science literature on GE (e.g. Bellamy et al., 2012). This argument is essentially that 'major geoengineering efforts may lead to reduced mitigation and/or adaptation efforts because of a premature conviction that geoengineering has provided "insurance" against climate change' (Royal Society, 2009: 37). In the words of one focus group participant, the same argument can be expressed as follows: 'Then we don't need to do anything. If we do this [i.e. deploy GE technologies] we don't have to do anything, because then it will be fixed anyway' (FG 7). The social science literature on GE argues that it is an empirical question whether GE research would bring about such reactions, or whether the mere idea of largescale engineering of the climate would instead lead people to put more effort into conventional mitigation to avoid deploying GE technologies. In the words of Bellamy et al. (2012: 601), 'it has been argued that even considering geoengineering could, in point of fact, galvanize mitigation efforts rather than harm them'. 
The moral hazard argument was identified as relevant in several of the focus groups (FG 2, 5, 7 and 8). However, participants' fear did not concern their own behaviour, but the risk that other people would be led to believe that lifestyle change was unnecessary. If the potential implementation of GE became widely discussed - for instance in response to the climate emergency argument, as discussed in Example 2 - focus group participants saw the risk of reduced efforts to cut GHG emissions. The participants repeatedly concluded that conventional mitigation, at both the individual and collective levels, should be prioritized over GE research and deployment and over adaptation measures.

\section{Governance and control}

In all focus groups except one (FG 3), participants emphasized aspects of governance, control and democracy. Preston (2011: 459) noted that 'concerns about social justice and geopolitical stability are clearly some of the most important ethical issues that geoengineering faces'. The focus group participants raised questions about who would have the power over GE technologies and how to regulate GE research and deployment. There was widespread scepticism as to whether it would be possible to control GE technologies, much in line with the scepticism discussed above as to whether the scientific community would be able to control and predict the negative ecological side-effects of GE deployment. This line of reasoning is illustrated by a quotation from one group of retirees:

\section{Example 3}

\begin{tabular}{|l|l|l|}
\hline 95 & Ben: & Who would have the power over it [i.e. GE]? \\
\hline 96 & David: & Who would regulate it? \\
\hline 97 & Eve: & $\begin{array}{l}\text { Often when people try to regulate nature and the Earth the final result isn't } \\
\text { that good. }\end{array}$ \\
\hline 98 & Moderator & $\begin{array}{l}\text { You mentioned governance problems before. Can you see any solutions to } \\
\text { that? Could global technologies be controlled? }\end{array}$ \\
\hline 99 & Ben: & $\begin{array}{l}\text { I think this could lead to war ... It would be something extraordinary, to } \\
\text { have power over this. Being able to decide that now you will freeze for a } \\
\text { while in that corner, and now we will be warm, and now we will get rain and } \\
\text { you don't get any rain. If you are nice to us you could buy some food from } \\
\text { us but at a very high cost. }\end{array}$ \\
\hline 100 & David: & No, that doesn't sound like a good solution. \\
\hline (FG 7) &
\end{tabular}


Example 3 highlights two key questions recurrently brought up in the focus groups, i.e. who would have power over GE and who would regulate the use of GE technologies. It is worth noting that, in this example, the moderator did not introduce these questions, but they were raised by two of the participants, Ben and David, and followed up by Eve in turn 97 arguing that attempts to govern nature are seldom successful.

Example 3 further illustrates an argument raised by the youngest and oldest participants (FG 2, 7 and 8), i.e. that developing GE could lead to conflict, and eventually warfare, over control of the new technologies and their side-effects, particularly in a future of ever scarcer natural resources. In turn 99, Ben answers the moderator's question about governance by describing a future with a clear 'us' and 'them', in which groups and societies are counterposed and power is in the hands of those who control GE technologies. In addition, in another group (FG 4), participants addressed the issue of global justice, arguing that if risky GE technologies are tested in developing countries, these could become doubly afflicted, both by the impacts of climate change and by the potential negative sideeffects of GE.

\section{Ways forward?}

In all focus groups, participants expressed pessimism regarding both GE's potential as a response to climate change and humankind's ability to mitigate climate change through conventional means. In particular, participants lamented that, despite the seriousness of climate change, short-term growth and profit interests are still prioritized at the individual, national and international levels.

Some potential solutions were nevertheless identified. As noted above, trust that politicians would deal with climate change was very low. The participants said that they wanted politicians to take responsibility for mitigation actions, but still saw both national governments and international bodies as very slow in taking action. However, when conventional mitigation strategies were counterposed to GE, the former were what most of the participants preferred. When confronted with the prospect of GE, the participants saw GHG emission reductions agreed through international negotiations as the most desirable strategy, despite their general low trust in political solutions. This is one of the most 
notable turning points in the focus group discussions: in light of possible GE deployment as a consequence of humanity's inability to slow or stop climate change, the UN process, previously dismissed by participants, was now reassessed, with few exceptions (FG 1 and 2), and described as the best way to counteract global warming. In addition, participants referred to advances in renewable energy production along with substantial lifestyle changes as solutions to the problem of anthropogenic climate change, instead of putting global ecosystems at risk through what they saw as dangerous GE experiments beyond human control.

It is noteworthy that technological responses to climate change did not by default arouse scepticism. In most focus groups, the participants expressed scepticism regarding GE technologies, instead proposing that a more appropriate response to climate change would be to develop low-carbon energy technologies, particularly technologies for producing renewable energy, such as solar, wind and hydro power. Renewables were viewed favourably because these technologies were assumed to use nature in an environmentally friendly way and to preserve, not threaten, nature.

\section{Discussion}

This paper set out to analyse how Swedish laypeople make sense of emerging ideas of the large-scale deliberate technical manipulation of the global climate, i.e. geoengineering. Sweden, similar to many other countries, constitutes a case of public GE ignorance, since there has been very limited public debate and low media attention. Across the focus groups, participants expressed great concern about climate change. However, GE largely aroused scepticism, particularly because it: could have negative environmental side-effects, addresses the symptoms rather than causes of climate change, could create moral hazard and could give rise to various governance challenges. In this respect, our focus groups display a different pattern from that identified in a UK study by Pidgeon et al. (2012), who suggested a correlation between concern about climate change and favourable attitudes towards GE.

Although the moderators' questions were open-ended and the participants received little guidance as to what aspects of GE to discuss, similar arguments recurred in the various groups. As the study was 
designed to include a broad selection of participants with different backgrounds and levels of interest in environmental issues, this was somewhat unexpected. It is particularly worth noting that arguments frequently voiced in the social science and the media discourse on GE were also raised in the focus groups, although the participants had not heard of GE before attending the focus group session. Despite the participants' previous unawareness of GE, they were able to problematize and criticize GE using many of the central aspects also identified in the scientific debate. In line with Carr et al. (2013) and Pidgeon et al. (2013), we maintain that laypeople can lead well-reasoned argumentation even with very limited input from experts.

Our analyses reinforce the importance of paying attention not only to what was said in the focus groups but also to how it was said, paying attention to the nuances in participants' statements, the communicative context of utterances and the participant interaction that shaped their representations of GE (cf. Marková et al., 2007; Smith and Joffe, 2012; Wibeck, 2014). This study demonstrated, among other things, that participants did not simply reject the idea of GE without substantial discussion; instead, social representations started to be formed in the focus groups through a process of trying out and negotiating arguments. Arguments in favour were suggested by some participants, for example, that it is important to 'think outside the box' and to consider new and science-fiction-like ideas when combating climate change. Nonetheless, when such arguments were proposed, the meaning exchanges tended to end up producing objections, for example, that the complexities, uncertainties and potential negative side-effects associated with GE outweigh the potential benefits of its development and deployment.

Also the recent assessment reports from the IPCC indicate that GE's uncertainties and environmental risks remain (IPCC, 2013). In the scientific and public debate, only few scientists declare any positive side-effects of implementing GE or confirm a better future with GE (Anshelm and Hansson, 2014; Linnér \& Wibeck, 2015). One could claim that, despite recent advances in modelling research, the same fundamental issues are still at stake, such as: What views of democracy inform global governance (Heyward and Rayner, 2013; Macnaghten and Szerszynski, 2013)? Does GE challenge 
democratic governance principles (Szerszynski et al. 2013)? Could the results of field experiments be scaled up and, if so, how (Lawrence and Crutzen, 2013; Robock and Kravitz, 2013)? Will uncertainties preclude meaningful scientific results and would such results even be meaningful in informing decision making (Fernow, 2012; Hansson, 2014)? Our focus groups suggest that these are latent concerns even among Swedish laypeople not specifically informed about GE.

The overall view of GE in the focus groups was so unfavourable that several groups thought they must be the most negative group in our sample. Not even the moderators' introduction of the emergency framing changed this negative view, despite the participants' expressing great concern about climate change. Although the participants seemed to view the moderators as cautious promoters of GE (because they introduced the emergency framing and were perceived as representing research and technical development) and many participants expressed optimism regarding both the improvement of existing technologies and the future potential of emerging technologies, their overall perceptions of GE were overwhelmingly sceptical. Perhaps this is at least partly due to the large-scale character of GE and the highly speculative prospect of humans' controlling natural systems. The moderator's mere mentioning the words 'large-scale' or 'artificial' in connection with some GE technologies seemed to trigger a whole range of sceptical connotations among the participants.

The focus group participants repeatedly criticized the growth ethos while articulating far-reaching demands for renewable technology, lifestyle change and societal transformation. Current consumption patterns were problematized and GE was deemed to make the situation worse. Concerns were raised that GE might strengthen, at least temporarily, unsustainable business as usual. The participants expressed concern that politicians, industry and other citizens might use GE as an excuse not to take other actions to mitigate the imminent climate crisis. In light of GE, the international political negotiations previously deemed pointless were upgraded and recognized as necessary and the way to manage climate change. To understand these views, we must consider the particularities of the Swedish case and contrast our results to those of previous research into public perceptions of GE from other country contexts. 
Stilgoe et al. (2013) argue that overarching questions about the purpose of research, trust in science and pathways of technological development that have been treated in public debate about genetically modified organisms and synthetic biology apply to GE as well. However, when anchoring their views on GE, it was more frequent among our focus group participants to draw analogies to the intense and controversial Swedish nuclear debate. Some informants even joked about organizing a referendum on GE, like the 1980 referendum on nuclear power in Sweden. The nuclear debate in Sweden lasted for two decades, was marked by intense conflict and is usually seen as a turning point in the lay questioning of experts. During the nuclear debate, experts' claims were gradually increasingly contested and also confronted with scientifically based counterclaims. The nuclear debate can be understood as broadly educating Swedish citizens in sociotechnical matters and profoundly reshaping their trust in expertise and scientists (Anshelm, 2000).

This scepticism may still be prevalent, or at least be recalled, when hazardous large-scale sociotechnical systems sharing characteristics with nuclear power are discussed. This might indicate that Swedish laypeople are especially aware of the potential environmental side-effects of grand-scale technologies and are therefore more sceptical than are citizens in many other countries. Nonetheless, there are good reasons for assuming that a similar pattern will appear in, for example, Germany, which Merk et al. (2014) claim could have among the most GE sceptical citizens in Europe and that has had a similar societal reaction to nuclear power.

Macnaghten and Szerszynski (2013) explain that the scepticism found in their UK focus groups may partly be explained by the introduction of alternative framings. This analysis can be contrasted to the experience in our study, in which informants were critical of GE both before and after being confronted with for example the emergency framing. The emergency framing seemed to strengthen the scepticism and prompted the reassessment of arguments favouring international political negotiations and conventional mitigation options, both these measures being considered more feasible and more desirable than GE. Politics was therefore reconsidered in light of the risks of GE, but contrary to what was expected it was in line with the reverse moral hazard argument. However, the 
method we applied and our limited empirics do not reveal much of the more general relation between GE and mitigation (c.f. Reynolds, 2014), but the topic definitely deserves further attention.

This paper has focused on the content of early social representations in Swedish lay focus groups, treating the notion of large-scale deliberate technical manipulations of the global climate rather than specific GE technologies as such. Future research should examine how such representations are formed, the communicative processes involved in forming and maintaining social representations and whether and how representations differ depending on the specific GE technologies discussed.

\section{Acknowledgements}

This research was funded by the Swedish Research Council (grant no. 2012-1101) and the Swedish Research Council Formas (grant no. 2012-725). We are grateful to the participants of the Environmental Humanities Collaboratory seminar at Linköping University and four anonymous reviewers for valuable comments on earlier versions of the paper. Thanks are also extended to the focus group participants for sharing their thoughts.

\section{References}

Anshelm, J. (2000). Mellan frälsning och domedag: Om kärnkraftens politiska idéhistoria $i$ Sverige 1945-1999 [Between salvation and doomsday: On the political history of ideas of nuclear power in Sweden 1945-1999]. Stockholm: Symposion.

Anshelm, J., \& Hansson, A. (2014). Battling Promethean dreams and Trojan horses: Revealing the critical discourses of geo-engineering. Energy Research \& Social Science, 2, 135-144.

Bellamy, R., Chilvers, J., Vaughan, N., \& Lenton, T. (2012). A review of climate geoengineering appraisals. WIREs Climate Change, 3, 597-615.

Carr, W., Preston, C., Yung, L., Szerszynski, B., Keith, D., \& Mercer, A. (2013). Public engagement on solar radiation management and why it needs to happen now. Climatic Change, 121, 567-577.

Corner, A., Parkhill, K., Pidgeon, N., \& Vaughan, N. (2013). Messing with nature? Exploring public perceptions of geoengineering in the UK. Global Environmental Change, 23, 938947.

Corner, A., \& Pidgeon, N. (2010). Geoengineering the climate: the social and ethical implications. Environment, 52, 24-37. 
Corner, A., \& Pidgeon, N. (2014, in press). Like artificial trees? The effect of framing by natural analogy on public perceptions of geoengineering. Climatic Change, DOI 10.1007/s10584-014-1148-6.

Crutzen, P. (2006). Albedo enhancement by stratospheric sulphur injections: a contribution to resolve a policy dilemma? Climatic Change, 77, 211-219.

Daamen, D., de Best-Waldhober, M., Damen, M., \& Faaij, A. (2006). Pseudo-opinions on CCS technologies. Paper presented at GHGT-8 (2006) Trondheim, Norway.

Fernow, H. (2012). Complex risks and the limits of cost-benefit analysis. In D. Amelung, W. Dietz, H. Fernow, D. Heyen, D. Reichwein, \& T. Wiertz (Eds.) Beyond Calculation (pp. 1218). Forum Marsilius-Kolleg 02(2012). Universität Heidelberg.

Fleming, J. (2010) Fixing the Sky:The Checkered History of Weather and Climate Control. New York: Columbia University Press.

Hamilton, C. (2013). Earthmasters: The Dawn of the Age of Climate Engineering. New Haven \& London: Yale University Press.

Hansson, A. (2014). Ambivalence in calculating the future: the case of re-engineering the world. Journal of Integrative Environmental Sciences, 2, 125-142.

Heyward, C., \& Rayner, S. (2013). A curious asymmetry: Social science expertise and geoengineering. CGG Working Paper 007. Retrieved from: http://www.geoengineeringgovernance-

research.org/perch/resources/workingpaper7heywardrayneracuriousasymmetry.pdf. Last accessed: Oct 14, 2014.

Höijer, B. (2010). Emotional anchoring and objectification in the media reporting on climate change. Public Understanding of Science, 19, 717-731.

IPCC (2007) Summary for Policymakers. In: Climate Change 2007: Mitigation. Contribution of Working Group III to the Fourth Assessment Report of the Intergovernmental Panel on Climate Change [B. Metz, O.R. Davidson, P.R. Bosch, R. Dave, L.A. Meyer (eds)], Cambridge and New York: Cambridge University Press.

IPCC (2013). Working Group I contribution to the IPCC 5th Assessment Report 'Climate Change 2013: The Physical Science Basis. [Stocker, T.F., D. Qin, G.-K. Plattner, M. Tignor, S.K. Allen, J. Boschung, A. Nauels, Y. Xia, V. Bex and P.M. Midgley (eds.)]. Cambridge and New York: Cambridge University Press.

Jarrett, R. (1993). Focus group interviewing with low-income minority populations. In: D. Morgan (Ed.) Successful focus groups: Advancing the state of the art (pp. 184-201). Newbury Park: Sage.

Kahan, D., Tarantola, T., Silva, C., Jenkins-Smith, H., \& Braman, D. (2012). Geoengineering and the Science Communication Environment: A Cross-Cultural Experiment. The Cultural Cognition Project, Working paper no. 92. Yale Law School. 
Kitzinger, J. (1994). The methodology of focus groups: the importance of interaction between research participants. Sociology of Health and Illness, 16, 103-121.

Lawrence, M., \& Crutzen, P. (2013). The evolution of climate engineering research. Opinion Article, Geoengineering Our Climate Working Paper and Opinion Article Series.

Linnér, B-O. \& Wibeck, V. (2015) Dual high-stake emerging technologies: a review of the climate engineering research literature. WIREs Interdisciplinary Reviews: Climate Change. Doi: $10.1002 /$ wcc.333

Macnaghten, P., \& Szerszynski, B. (2013). Living the global social experiment: An analysis of public discourse on solar radiation management and its implications for governance.

Global Environmental Change, 23, 465-474.

Marková, I., Grossen, M., Linell, P,. \& Salazar Orvig, A. (2007). Dialogue in Focus Groups: Exploring Socially Shared Knowledge. London: Equinox.

Markusson, N., Kaltenbrunner, A., Laniado, D., \& Venturini, T. (2013). Bounding boundaries: the construction of geoengineering on wikipedia. CGG Working Papers 005. Retrieved from: http://geoengineering-governanceresearch.org/perch/resources/workingpaper5markusson-et-algeinccwikipediadataset.pdf. Last accessed: Oct 14, 2014.

Mercer, A., Keith, D., \& Sharp, J. (2011). Public understanding of solar radiation management. Environmental research letters. Vol 6 (4).

Merk, C,. Pönitzsch, G,. Kniebes, C,. Rehdanz, K., \& Schmidt, U. (2014). Exploring public perception of solar radiation management. Kiel Institute for the World Economy, Kiel Working Paper no. 1892.

Morgan, D. (1997). Focus groups as qualitative research. 2nd ed. Newbury Park: Sage.

Moscovici, S. (1973). Foreword. In C. Herzlich (Ed.) Health and illness: a social psychological analysis (pp. ix-xiv). London: Academic Press.

Moscovici, S. (1984). The phenomenon of social representations. In R. Farr, \& S. Moscovici (Eds) Social Representations (pp. 3-69). Cambridge: Cambridge University Press.

NERC (2010). Experiment earth? Report on a public dialogue on geoengineering. National Environment Research Council. Retrieved from:

http://www.nerc.ac.uk/about/whatwedo/engage/engagement/geoengineering/geoengineeringdialogue-final-report.pdf. Last accessed: Sep 25, 2014.

Olausson, U. (2011). 'We're the ones to blame': Citizens' representations of climate change and the role of the media. Environmental Communication, 5, 281-299.

Petersen, A. (2014). The emergence of the geoengineering debate within the IPCC. Geoengineering Our Climate Working Paper and Opinion Article Series. Retrieved from: http://wp.me/p2zsRk-bp. Last accessed: Sep 26, 2014. 
Pidgeon, N., Corner, A., Parkhill, K., Spence, A., Butler, C., \& Poortinga, W. (2012). Exploring early public responses to geoengineering. Philosophical Transactions of the Royal Society A, 370, 4176-4196.

Pidgeon, N. Parkhill, K., Corner, A., \& Vaughan, N. (2013). Deliberating stratospheric aerosols for climate geoengineering and the SPIGE project. Nature Climate Change, 3, 451457.

Porter, K., \& Hulme, M. (2013). The emergence of the geoengineering debate in the UK print media: A frame analysis. Geographical Journal, 179, 343-355.

Poumadere, M., Bertoldo, R., \& Samadi, J. (2011). Public perceptions and governance of controversial technologies to tackle climate change: nuclear power, carbon capture and storage, wind, and geoengineering. WIREs Climate Change, 2, 712-727.

Preston, C. (2011). Re-thinking the unthinkable: Environmental ethics and the presumptive argument against geoengineering. Environmental Values, 20, 457-479.

Reynolds, J (2014) A critical examination of the climate engineering moral hazard and risk compensation concern. The Anthropocene Review, 1-18.Robock, A., \& Kravitz, B. (2013). Use of models, analogs, and field-tests for geoengineering research. Geoengineering Our Climate? Ethics, Politics and Governance. Opinion Article 29 October, 2013. Retrieved from: http://www.geoengineeringourclimate.com. Last accessed: Sep 26, 2014.

Royal Society (2009). Geoengineering the climate: science, governance and uncertainty. London: The Royal Society.

Smith, N. \& Joffe, H. (2012). How the public engages with global warming: A social representations approach. Public Understanding of Science, 22, 16-32.

Stilgoe, J., Watson, M., \& Kuo, K. (2013). Public engagement with biotechnologies offers lessons for the governance of geoengineering research and beyond. PLoS Biology, 11, e1001707.

Szerszynski, B., Kearnes, M., Macnaghten, P., Owen, R. \& Stilgoe, J. (2013) Why SRM geoengineering and democracy won't mix. Environment and Planning A, 45, 2809-2816.

Wibeck, V. (2014). Social representations of climate change in Swedish lay focus groups: local or distant, gradual or catastrophic? Public Understanding of Science, 23, 204-219.

Wibeck, V., Öberg, G., \& Abrandt-Dahlgren, M. (2007). Learning in focus groups: an analytical dimension for enhancing focus group research. Qualitative research, 7, 249-262.

Wilkinson, S. (1998). Focus groups in health research: exploring the meanings of health and illness. Journal of Health Psychology, 3, 329-348.

Wright, M.J., Teagle, D.A.H., \& Feetham, P.M. (2014). A quantitative evaluation of the public response to climate engineering. Nature Climate Change, 4, 106-110. 
